\title{
Impact of Tibetan Plateau on North African precipitation
}

\author{
Zhihong Chen ${ }^{1} \cdot$ Qin Wen ${ }^{2} \cdot$ Haijun Yang $^{3}$ (D)
}

Received: 4 January 2021 / Accepted: 3 June 2021 / Published online: 12 June 2021

(c) The Author(s) 2021

\begin{abstract}
The Tibetan Plateau (TP) plays an important role in regulating the global hydrologic cycle. Using a fully coupled climate model, we conduct sensitivity experiments to quantify the impact of the TP on North Africa precipitation. Removing the TP in the model can enhance North African precipitation. Specifically, North Africa precipitation increases substantially during the rainy season (from May to October) though it remains unchanged during the dry season (from November to April). During the rainy season, the TP's absence in the model causes an anomalous moisture transport from the Indian Ocean and tropical Atlantic to North Africa, which enhances the moisture convergence over North Africa and increases precipitation there. Later on, the change in the Atlantic, that is, cooling (warming) in the North (South) Atlantic forces a southward cross-equatorial moisture transport anomaly from North Africa to the equatorial Atlantic, decreasing the moisture convergence over North Africa and thus precipitation. In general, the moisture convergence is strengthened in most regions of North Africa due to the TP removal, so the resultant precipitation is increased. During the dry season, atmospheric convection center over the Africa continent is located mainly south of the equator, and there is almost no anomalous moisture transport toward North Africa in response to the TP removal. These results suggest that the uplift of the TP may have led to North African aridity.
\end{abstract}

\section{Introduction}

The Tibetan Plateau (TP) is a vast elevated plateau over Central and East Asia. With an area of about 2.5 million square kilometers and an averaged elevation exceeding $4000 \mathrm{~m}$, it is sometimes called as the "Third Pole" of the world. Paleogeological evidence suggests that the significant uplift of the TP occurred about $8 \mathrm{Ma}$ (million years ago) (Harrison et al. 1992; Molnar et al. 1993), which has had profound effects on Asian and global climate (Flohn and Reiter 1968; Yeh and Gao 1979; Kutzbach et al. 1993; Ruddiman et al. 1997; Zhou et al. 2009; Wu et al. 2012). Particularly, it may have played a crucial role in regulating the global hydrologic cycle $(\mathrm{Lu}$ et al. 2005; Xu et al. 2008, 2014; Chen et al. 2012; Curio

Haijun Yang

yanghj@fudan.edu.cn

1 Department of Atmospheric and Oceanic Sciences, School of Physics, Peking University, Beijing 100871, China

2 School of Geography, Nanjing Normal University, Nanjing 210023, China

3 Department of Atmospheric and Oceanic Sciences, Institute of Atmospheric Science, and CMA-FDU Joint Laboratory of Marine Meteorology, Fudan University, 2005 Songhu Road, Shanghai 200438, China et al. 2015). The TP can serve as a "water tower," because of its abundant water resources and its influences on long-distance moisture transport at the global scale (Xu et al. 2008, 2014). Chen et al. (2012) suggested the TP is responsible for the moisture transport from the surface layer to stratosphere, which can affect the global troposphere-stratosphere moisture budget.

North Africa, located in the subtropical zone of the Northern Hemisphere (NH), is one of the most well-known arid regions in the world. The Sahara Desert covers much of North Africa, which is the world's largest hot desert with an area of about nine million square kilometers (Tucker et al. 1991); it is characterized by high temperature and extreme aridity. The annual precipitation in the Sahara Desert is less than $100 \mathrm{~mm}$ on average; and it is even less than $5 \mathrm{~mm}$ in some areas (Faure and Denard, 1998). As an important geological event, the formation of the Sahara Desert can be dated back to the Late Miocene (10-8 Ma) (Schuster et al. 2006; Zhang et al. 2014), which is roughly coincident with the timing of the TP uplift. Therefore, the aridity in North Africa might have some connetions with the TP uplift for a certain degree.

In fact, some studies already suggested a connection between the TP uplift and North African aridity. For example, Rodwell and Hoskins (1996) proposed a concept that the 
Asian monsoons associated with the TP are remote forcing to the dry climate of North Africa. Ruddiman et al. (1997) showed that the TP uplift can cause drying in the north and west of the TP, and then the dry air can be conveyed southwestward to the Caspian Sea, Arabia and Northwest Africa, resulting in North African aridity. Some studies suggested that the Atlantic Meridional Overturning Circulation (AMOC) can affect North African precipitation (Mulitza et al. 2008; Stuut, 2008; Castañeda et al. 2009; Woollings et al. 2012). Recent studies showed that the TP uplift may have played a critical role in the AMOC formation (Maffre et al. 2018; Su et al. 2018; Yang and Wen 2020; Yang et al. 2020). In this paper, we propose a linkage among the TP uplift, North African desertification and AMOC formation. We emphasize that the indirect impact of ocean circulation change on North African precipitation should be considered when exploring the impact of the TP uplift on North African desertification.

In a normal situation, the TP acts as a heat source during the boreal summer, causing intense upward motion over the TP and strengthening the summer monsoon (Kutzbach et al. 1989; Liu and Yin 2002; Duan and Wu 2005), whereas during the boreal winter it acts as a heat sink (Ji et al. 1986; Yanai et al. 1992). In the arid and semi-arid regions, such as North Africa, seasonal variation of precipitation is particularly notable (Wai et al. 1997; Chikako and Harada 2003). Therefore, we will focus on the seasonal variation of precipitation in North Africa in this paper. Both coupled model and slab-ocean model sensitivity experiments in this study show a significant increase in North African precipitation during the rainy season (from May to October) in response to the TP removal, while the precipitation during the dry season (from November to April) is insensitive to the TP perturbation.

This paper is organized as follows. Model and experiments are described in Sect. 2. Changes in precipitation, humidity and temperature are analyzed in Sect. 3. Major processes and mechanisms for precipitation change are investigated in Sect. 4, followed by summary and discussion in Sect. 5.

\section{Model and experiments}

The Community Earth System Model (CESM1.0) of the National Centre for Atmospheric Research (NCAR) is used in this study. It is a fully-coupled, global climate model, which consists of five components and one coupler: the Community Atmosphere Model (CAM5) (Park et al. 2014), the Community Land Model (CLM4) (Lawrence, 2012), the Community Ice Code (CICE4) (Hunke and Lipscomb 2010), the Parallel Ocean Program (POP2) (Smith and Gregory 2009), the Community Ice Sheet Model (Glimmer-CISM), and the CESM Coupler (CPL7). CESM1.0 has been widely used and validated by researchers in the community. The model grid employed in this study is T31_gx3v7. The CAM5 has 26 vertical levels, with finite volume nominal $3.75^{\circ} \times 3.75^{\circ}$ in the horizontal. The CLM4 has the same horizontal resolution as the CAM5. The POP2 has 60 vertical levels, and a uniform $3.6^{\circ}$ spacing in the zonal direction. In the meridional direction, the ocean grid is non-uniformly spaced: it is $0.6^{\circ}$ near the equator, gradually increasing to the maximum $3.4^{\circ}$ at $35^{\circ} \mathrm{N} / \mathrm{S}$ and then decreasing poleward. The CICE4 has the same horizontal grid as the POP2. No flux adjustments are used during integration of the CESM1.0.

Two groups of experiments are performed to examine the consequences of changes of the TP topography (Fig. 1). The first group includes a control run with realistic topography (Fig. 1a) and a sensitivity experiment without the TP topography (Fig. 1b). The control run, named "Real," is 2400-year integration, reaching its quasi-equilibrium (QE) after 1000 years of integration (Yang et al. 2015). The sensitivitye experiment, named "NoTibet," starts from year 2001 of Real, and is integrated for 400 years, in which the topography around the TP is replaced by $50-\mathrm{m}$ land mass above the sea level. The second group includes two experiments. One is named "Flat," in which the global topography is set to 50-m land mass above the sea level (Fig. 1c). The other is named "OnlyTibet," in which the topography outside the TP area is set to 50-m land mass above the sea level, while the TP topography remains unchanged (Fig. 1d). Except for the topography, all other conditions in these experiments use the standard configuration with a preindustrial $\mathrm{CO}_{2}$ level of $285 \mathrm{ppm}$. The outputs in each experiment from year 2001 to year 2400 are used for analysis. The changes in North African climate due to the TP removal are obtained by subtracting the results of Real from those of NoTibet; the changes due to the uplift of the TP are obtained by subtracting the results of Flat from those of OnlyTibet. North African region studied in this work is outlined by dashed red contour in Fig. 1. The QE change in NoTibet (OnlyTibet) with respect to Real (Flat) is defined as the change averaged over the last 100 years of the 400 -year integration. The North African climate changes due to the TP removal and uplift have roughly the opposite phases, but with the same amplitude. Therefore, in the paper we focus mainly on the results from NoTibet and Real. These experiments are the same as those used in Yang and Wen (2020), Wen and Yang (2020) and Yang et al. (2020).

To separate the effects of atmospheric dynamics and ocean dynamics, we carry out two slab-ocean experiments using CESM1.0, in which the dynamic ocean model is replaced by a mixed-layer ocean model. The atmospheric component CAM5 employs f19_gx1v6 resolution configuration, that is, with the finite volume nominal $1.9^{\circ} \times 2.5^{\circ}$ 


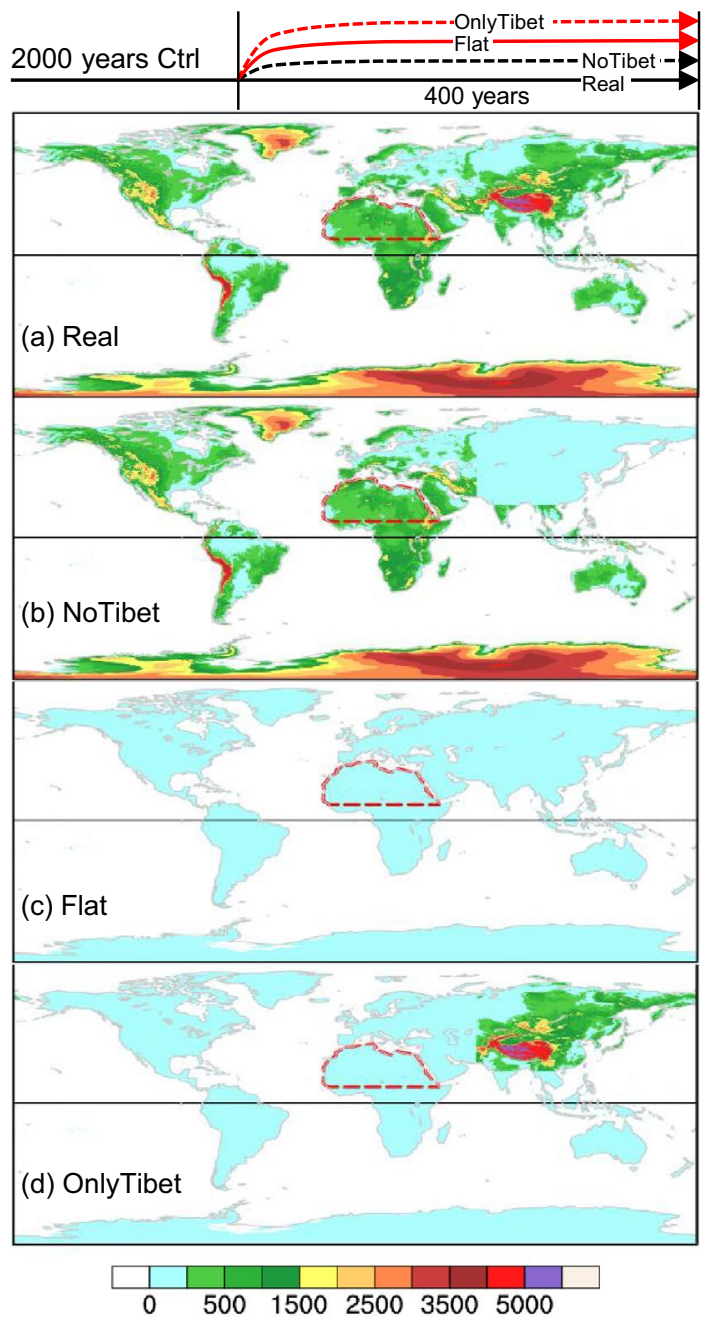

Fig. 1 Topography configuration in coupled model experiments. a Realistic topography used in the control run (Real), b modified topography without the Tibetan Plateau (TP) used in NoTibet, c global flat topography used in Flat, and $\mathbf{d}$ modified topography with only TP topography used in OnlyTibet. The dashed red curve outlines North Africa, with its southern boundary at $10^{\circ} \mathrm{N}$. The top panel shows the integration lengths of these experiments

in the horizontal. The slab-ocean model is integrated using the climatological mixed-layer depth (MLD) from Real and no interactive ocean dynamics is considered. It uses the ocean grid gx1v6 with the displaced North Pole located at Greenland. The horizontal grid has a uniform $1.125^{\circ}$ spacing in the zonal direction, and non-uniform spacing in the meridional direction, with resolution of $0.27^{\circ}$ near the equator, extending to the maximum $0.65^{\circ}$ at $60^{\circ} \mathrm{N} / \mathrm{S}$ and then shrinking gradually to the poles. The sea-ice component CICE4 has the same horizontal grid as the ocean model. No flux adjustments are used. The high-resolution experiments include a control run with realistic topography and a sensitive experiment without the TP topography. The control run, named "Real_SOM_f19," is integrated for 160 years.
The sensitivity experiment, named "NoTibet_SOM_f19," starts from year 101 of "Real_SOM_f19" and is integrated for 60 years. These two experiments reach quasi-equilibrium quickly because there is no dynamic ocean, and the QE change in NoTibet_SOM_f19 is defined as the change averaged over the last 30 years of the experiment. The North African climate changes due to the TP removal are obtained by subtracting the results of Real_SOM_f19 from those of NoTibet_SOM_f19, which can only be attributed to atmospheric processes.

The Mann-Kendall trend test is used to examine the statistical significance of our results. Most changes in selected regions are significant over the $95 \%$ confidence level, which is expected because altering the TP topography induces very strong mechanical forcing and strong responses around the globe. For visual clarity, we only show significance test in Figs. 3 and 6.

\section{Changes in North African precipitation, humidity and temperature}

\subsection{Seasonal cycle of precipitation}

The seasonal cycles of precipitation in both the observation and experiments are distinct, with peak rainfall of about 60-100 mm in August and little rain in January. Figure 2 shows seasonal variations of precipitation averaged over North Africa in Real, NoTibet, Flat, and OnlyTibet; it also shows the changes in NoTibet and OnlyTibet with respect to Real and Flat, respectively. The observed long-term monthly mean precipitation is obtained from the Climate Prediction Center (CPC) Merged Analysis of Precipitation (CMAP) (Xie and Arkin 1997). The North African area is indicated by the dashed red contour in Fig. 1, with its southern boundary at $10^{\circ} \mathrm{N}$. The observed precipitation in North Africa reaches its minimum (less than $10 \mathrm{~mm}$ ) in January, and increases gradually and peaks in August (about $70 \mathrm{~mm}$ ) (Fig. 2, grey curve). Such seasonal variation is closely related to the north-south shift of the intertropical convergence zone (ITCZ) (Chris et al. 1991; Hulme 1992). The climatological seasonal cycles of precipitation in both coupled model and slab-ocean experiments have the same phase as that of the observation, with the maximum (minimum) precipitation in August (January), but their amplitude is quite different (Fig. 2).

The absence (presence) of the TP tends to enhance (weaken) the precipitation in North Africa during the rainy season (Fig. 2, dotted curves). The North African precipitation can be divided into dry season and rainy season (Lamb 1983; Knippertz et al. 2008). Here, the rainy (dry) season is defined from May to October (from November to April). The changes of seasonal precipitation in NoTibet and OnlyTibet 


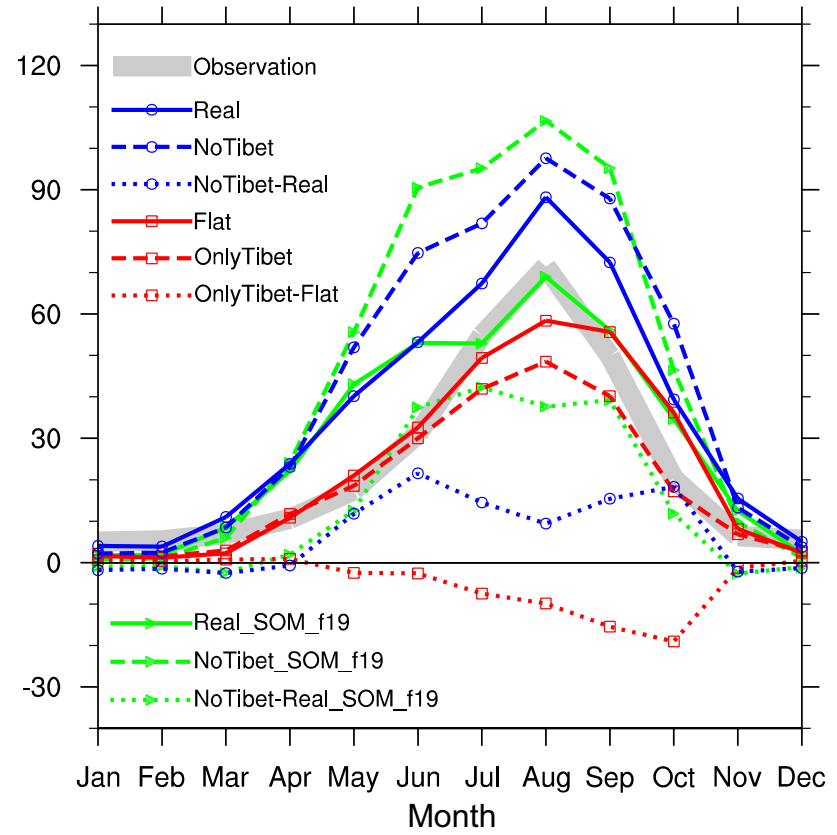

Fig. 2 Climatological seasonal cycles of precipitation over North Africa (units: $\mathrm{mm}$ ) in different experiments. Blue curves for Real (solid) and NoTibet (dashed), and for precipitation change in NoTibet (dotted) with respect to Real. Red curves for Flat (solid) and OnlyTibet (dashed), and for precipitation change in OnlyTibet (dotted) with respect to Flat. Green curves for Real_SOM_f19 (solid) and NoTibet_ SOM_f19 (dashed), and for precipitation change in NoTibet_SOM f19 (dotted) with respect to Real_SOM_f19. Thick grey curve shows the CMAP precipitation. Climatological seasonal cycle is obtained from the quasi-equilibrium stage of each experiment (i.e., Stage-II marked in Fig. 5), and averaged over the North African area shown in Fig. 1

are roughly of the same amplitude but with the opposite phases, particularly during the rainy season (dotted blue and red curves). In response to the TP uplift, the North African precipitation decreases slightly at the beginning of the rainy season, but decreases dramatically during the mid and late rainy season; during the dry season, the precipitation is hardly changed (dotted red curve). In response to the TP removal, the North African precipitation increases significantly during the whole rainy season (dotted blue curve), which can be seen more clearly in the patterns of monthly precipitation change (Fig. 3). In NoTibet_SOM, the North African precipitation increases much more than that in NoTibet (dotted green vs. dotted blue curves), suggesting that atmospheric processes are more important than oceanic process in North African precipitation increase. This point will be elaborated in Fig. 5.

In the coupled model experiment (NoTibet), the monthly precipitation changes in North Africa during the dry season are negligible (Fig. $3 \mathrm{a}-\mathrm{c}$ ). During the rainy season, precipitation is increased in most parts of North Africa (Fig. 3d-f), except for some decrease at the southern edge of
North Africa in August (Fig. 3e). Note that the precipitation change outside North Africa appears to be more remarkable than that in North Africa. However, the percentage change in North African precipitation is much more remarkable than that in its surrounding regions (Fig. $3 \mathrm{~g}-\mathrm{i}$ ). This suggests that North African precipitation is much more sensitive than precipitation in the other regions to the continental-scale TP topography change. In the slab-ocean experiment (NoTibet SOM), the monthly precipitation changes in North African region (Fig. 4) are similar to those in NoTibet (Fig. 3), while those over the Atlantic Ocean are very different in these two experiments. We will show in Fig. 5 that the slab-ocean results are qualitatively consistent with the coupled model results in the transient stage, during which the ocean dynamics has yet to play the role in North African climate change. In the following sections, we will focus on the precipitation change during the rainy season, which is represented by August, September and October (ASO). All analyses in the following sections are based on the ASO outputs.

\subsection{Temporal evolution}

In response to the TP removal, North African precipitation shows a remarkable increase in the transient stage (StageI) and a slow recovery in the later stage (Fig. 5a, green curve). The quasi-equilibrium change (Stage-II) in North African precipitation is less remarkable than the change in Stage-I. Specifically, coupled model experiments show that the ASO total precipitation is increased immediately by about $60-70 \mathrm{~mm}$ in Stage-I, and then starts to decrease gradually after year 150 . It reaches quasi-equilibrium in about 300 years. The final precipitation increase is about 30-40 mm. Both surface air specific humidity and air temperature (SAT) changes that are averaged over North Africa show similar temporal evolution to that of precipitation (Fig. 5a, blue and red curves). Surface air specific humidity is increased by about $1.0 \mathrm{~g} / \mathrm{kg}$ in Stage-I, but the final increase in Stage-II is only about $0.3 \mathrm{~g} / \mathrm{kg}$ (Fig. 5a, blue curve). SAT is decreased by about $0.6{ }^{\circ} \mathrm{C}$ in Stage-I, and is ultimately decreased by about $1.0^{\circ} \mathrm{C}$ in Stage-II (Fig. 5a, red curve). In response to the TP uplift, temporal evolutions of precipitation, specific humidity and SAT (Fig. 5b) are roughly opposite to those in response to the TP removal. In the two sets of paired coupled model experiments, precipitation, surface air specific humidity, and SAT changes are distinctly different in Stage-I and Stage-II (Fig. 5a, b).

Results from slab-ocean experiments can help us understand different behaviors in different stages of the coupled model results. In both Fig. 2 (green curves) and Fig. 5 (dashed curves), in response to the TP removal, the North African precipitation increase in NoTibet_SOM is much bigger than that in NoTibet. In fact, in both NoTibet and OnlyTibet, their initial precipitation changes are about $40 \%$ stronger 

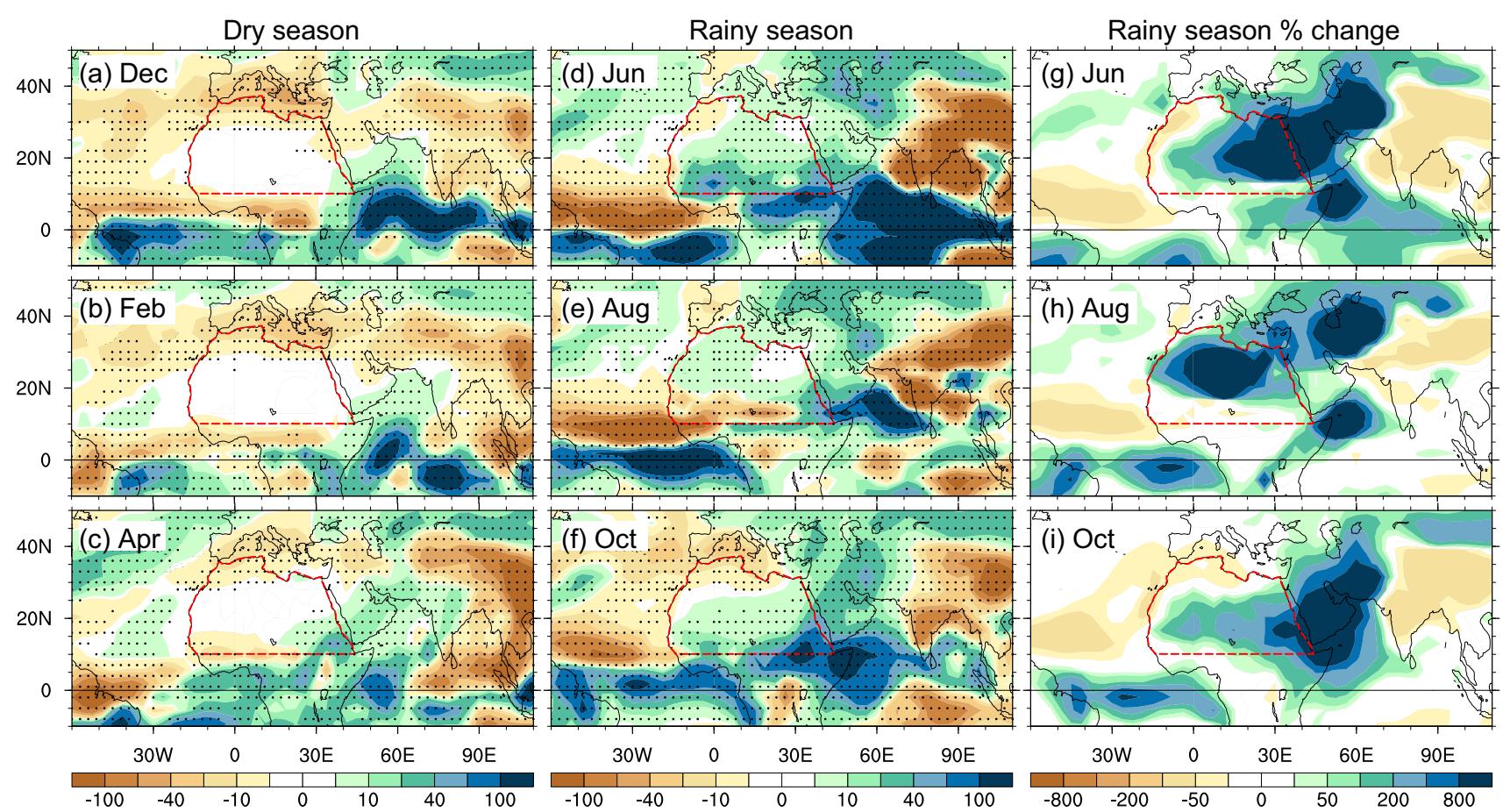

Fig. 3 Spatial patterns of monthly precipitation changes (units: $\mathrm{mm}$ ) in (left column) dry season and (middle column) rainy season in NoTibet with respect to Real. Data of quasi-equilibrium stage (StageII in Fig. 5) are used. a-c are for December, February and April; d-f are for June, August and October. (Right column) Spatial patterns

of precipitation percentage change (units: \%) in the rainy season in NoTibet. $\mathbf{g}-\mathbf{i}$ are for June, August, and October. Stippling in $\mathbf{a}-\mathbf{f}$ indicates changes exceeding the $95 \%$ significance level according to the Mann-Kendall trend test

\section{Dry season}
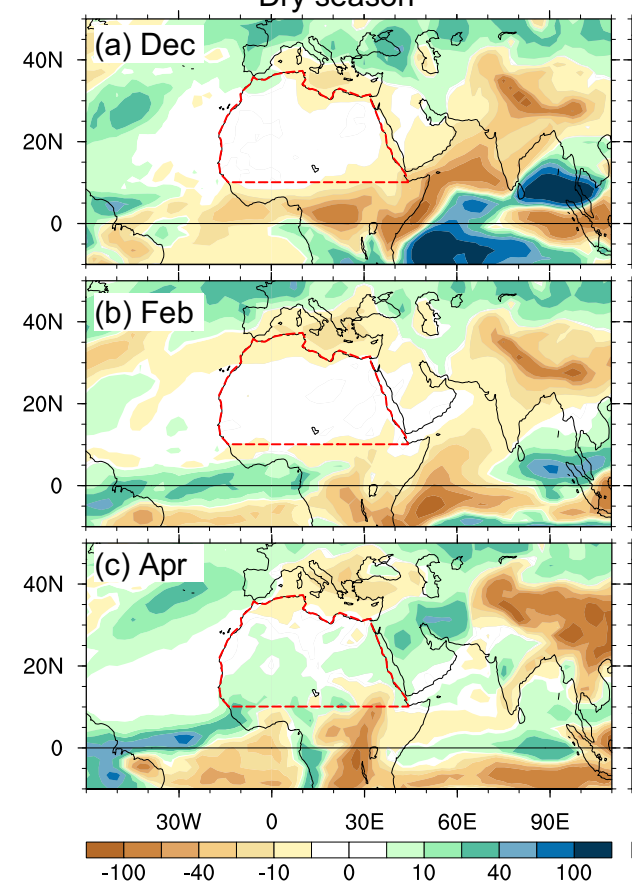

Rainy season
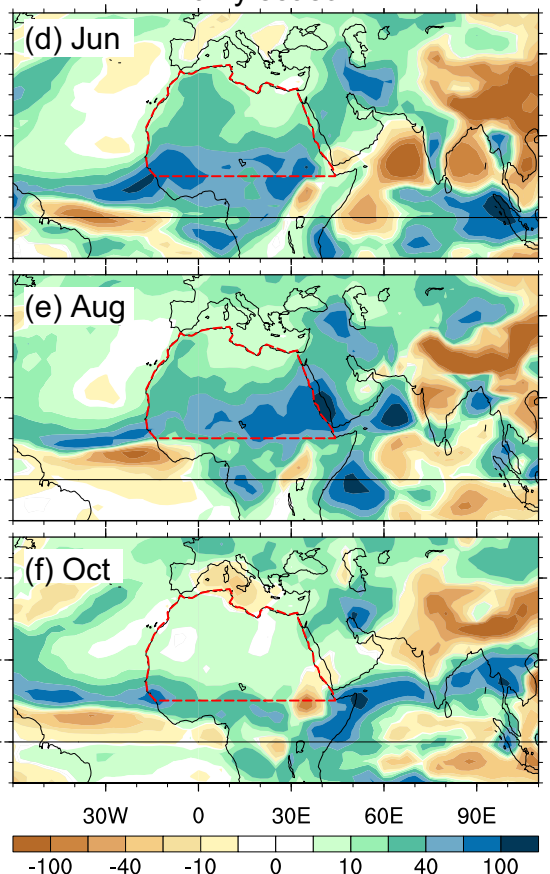

Rainy season \% change
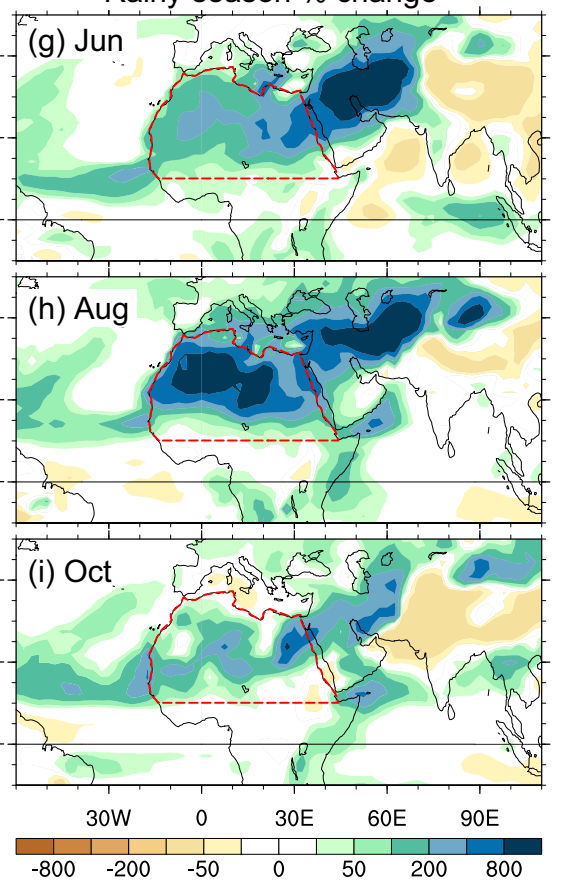

Fig. 4 Same as Fig. 3, but for changes in NoTibet_SOM_f19 with respect to Real_SOM_f19 


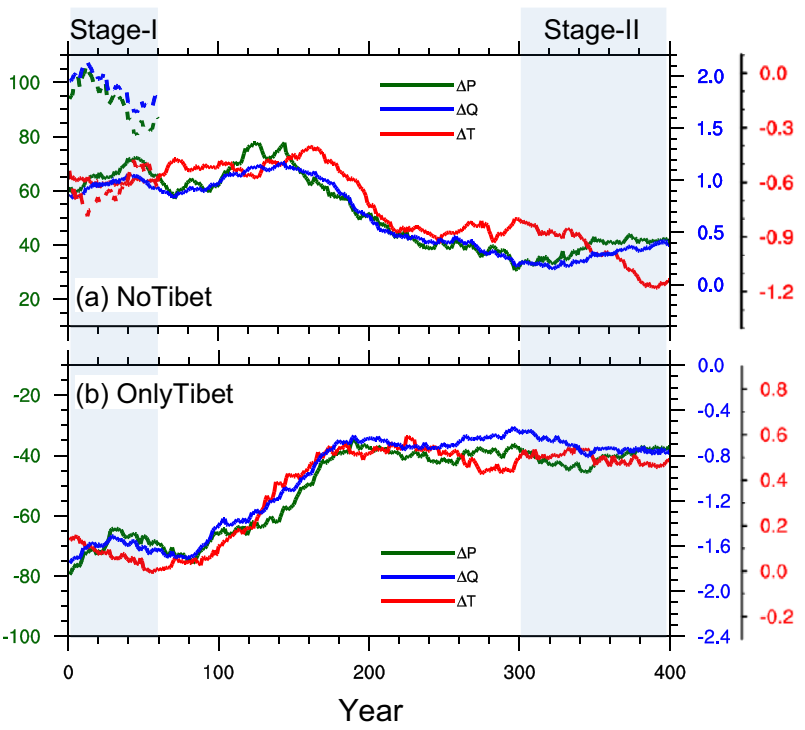

Fig. 5 Temporal evolution of changes in precipitation $(\mathrm{mm}$; dark green curve), surface air specific humidity (g/kg; blue curve) and SAT $\left({ }^{\circ} \mathrm{C}\right.$; red curve) during the rainy season. a Changes in NoTibet (solid curves) and NoTibet_SOM_f19 (dashed curves) with respect to Real and Real_SOM_f19, respectively. b Changes in OnlyTibet with respect to Flat. The y-axis label on the left is for precipitation; the blue and red labels on the right are for air specific humidity and SAT, respectively. Note that the integration length of NoTibet_SOM_f19 is only 60 years. All data are averaged over the North African area shown in Fig. 1

than those in the final quasi-equilibrium stage (Fig. 5a, b), during which the oceans have not changed much. This implies that the slow ocean evolution tends to offset the effect of the quick atmospheric process on North African precipitation change. This is also supported by the slabocean experiments. Here, we also note that the precipitation response in NoTibet_SOM is stronger than that in Stage-I of NoTibet (Fig. 5a). This can be partly attributed to different resolutions of the atmosphere model used in NoTibet_SOM and NoTibet: the former uses f19 with $1.9^{\circ} \times 2.5^{\circ}$ in the horizontal, while the latter employs T31 with finite volume nominal $3.75^{\circ} \times 3.75^{\circ}$ in the horizontal. In Sect. 4 , we will further show that the changes in Stage-I are the direct consequence of the TP removal (uplift) that mainly involves atmospheric processes, while the changes in Stage-II are attributed to the change in the Atlantic Ocean; the latter, in turn, is one of the consequences of the TP change (Yang and Wen 2020).

\subsection{Spatial pattern}

The spatial patterns of precipitation changes show clearly that in response to the TP removal, ASO total precipitation increases throughout the whole North Africa in StageI, with $30 \mathrm{~mm}$ in the north and more than $100 \mathrm{~mm}$ in the south (Fig. 6a). The pattern and magnitude of precipitation change in Stage-I are in good agreement with precipitation change in the slab-ocean experiment (Fig. 4d-f), suggesting again that precipitation change in this stage is mainly attributed to the atmospheric processes. In Stage-II, there is less precipitation in North Africa, compared with Stage-I (Fig. 6a vs Fig. 6d). Even so, the precipitation in NoTibet is still higher than that in Real, except at the southwest corner (Fig. 6d). Consistent with the enhanced precipitation, the specific humidity in the whole air column is increased in both stages (Fig. 6g, blue curves). The change in specific humidity mainly occurs below $700 \mathrm{hPa}$ and gradually increases to the maximum near the surface (Fig. 6b). This change in Stage-II is smaller than that in Stage-I. The spatial patterns of changes in surface air specific humidity (Fig. 6b,
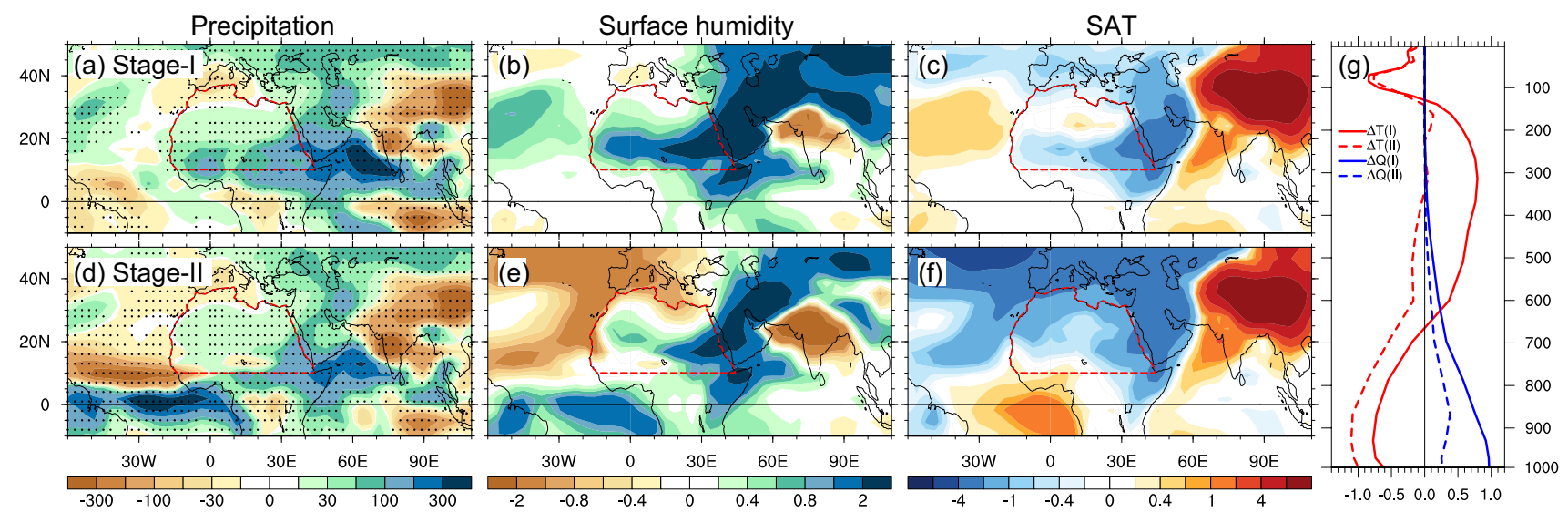

Fig. 6 Spatial patterns of changes in precipitation, surface air specific humidity and SAT during the rainy season in NoTibet with respect to Real. a-c Show Stage-I, and $\mathbf{d}-\mathbf{- f}$, Stage-II. $\mathbf{g}$ Vertical profiles of changes in air temperature $\left({ }^{\circ} \mathrm{C}\right.$; red curve) and air specific humidity (g/kg; blue curve) in Stage-I (solid) and Stage-II (dashed), averaged over the North African area shown in Fig. 1. Stipping in a, $\mathbf{d}$ indicates changes exceeding the $95 \%$ significance level according to the MannKendall trend test 
e) are in good agreement with those of precipitation change (Fig. 6a, d). Although the absolute amount of precipitation change over North Africa is smaller than that over the surrounding regions (Fig. 6a, d), the percentage change of precipitation increase over North Africa is the most significant, and can be more than 500\% (Fig. 3g-i), which is enough to affect vegetation growth over the desert. In other words, the TP uplift may have played an important role in the aridification of North Africa.

The air temperatures over North Africa show a strong cooling below $700 \mathrm{hPa}$ (Fig. 6g, red curves). The lowerlevel atmosphere cooling in Stage-II is stronger than that in Stage-I. Since the lower-level air temperature is crucial to surface evaporation and atmospheric moisture transport, we will focus on SAT next. In Stage-I, the SAT change over the Atlantic shows warming in the tropical Atlantic and cooling in the subpolar Atlantic (Fig. 6c). The SAT change over North Africa shows a cooling generally. In Stage-II, the SAT pattern is markedly different from that in Stage-I. Except in the TP region, there is a significant cooling of more than $4{ }^{\circ} \mathrm{C}$ in the Northern Hemisphere and a warming of about $1{ }^{\circ} \mathrm{C}$ in the Southern Hemisphere (Fig. 6f). The SAT change in Stage-II is a consequence of the ocean change, specifically, the AMOC shutdown in response to the TP removal. Detailed ocean processes were discussed in Yang and Wen (2020). The SAT change dominates the change in the atmosphere circulation over the tropical Atlantic. We want to emphasize again that the changes in pattern and magnitude of atmospheric variables, as well as their vertical profiles in
Stage-I of the coupled model experiment NoTibet are very similar to those in the slab-ocean experiment NoTibet_SOM, and the figures from NoTibet_SOM will not be presented for simplicity.

\section{Mechanism for precipitation change}

The causes for the arid climate in North Africa are complex, and have been studied comprehensively (deMenocal 1995; Rodwell and Hoskins 1996; Kutzbach and Liu 1997; Ruddiman et al. 1997; Pausata et al. 2020). One reason is that the moisture transported from the Indian Ocean and tropical Atlantic can hardly reach North Africa. During the dry season, the ITCZ moves southward to the equator and the northeasterly winter monsoon dominates over the tropical Asian continent (Fig. 7a). There is almost no moisture transport from the south through cross-equator flows. Descending motion dominates over North Africa, with ascending motion over the equator and to the south (Fig. 7b). During the rainy season, the ITCZ moves northward, and the summer monsoon dominates the tropical Asian continent (Fig. 7c). There are strong cross-equator airflows from the Indian Ocean and southern tropical Atlantic. However, the TP plays an important role in attracting the moisture transport from the Indian Ocean to South Asia, preventing the moisture from reaching North Africa (Fig. 7c). The descending motion over North Africa is much weaker than that in the dry season (Fig. 7d), which provides a favorable condition for precipitation in this
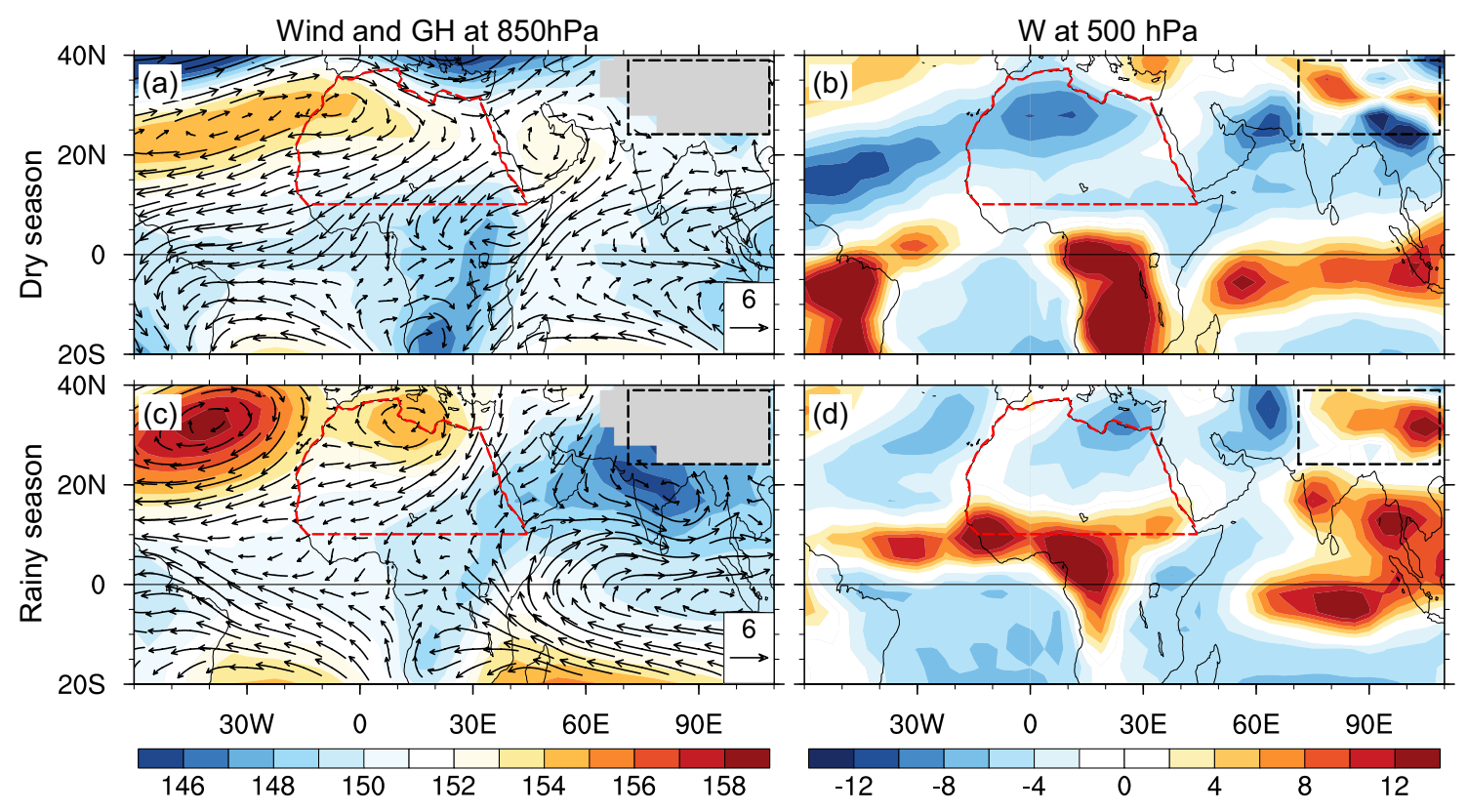

Fig. 7 Climatological a, c geopotential height (shading; units: $10 \mathrm{~m}$ ) and wind (vector; units: $\mathrm{m} / \mathrm{s}$ ) at $850 \mathrm{hPa}$ and $\mathbf{b}$, d vertical velocity (units: $10^{-1} \mathrm{~m} / \mathrm{s}$ ) at $500 \mathrm{hPa}$ in Real. a, b are for the dry season, and $\mathbf{c}$, d, for the rainy season. The dashed black box outlines the TP region $\left(70^{\circ}-110^{\circ} \mathrm{E}, 20^{\circ}-40^{\circ} \mathrm{N}\right)$. In $\mathbf{b}, \mathbf{d}$, positive (negative) value denotes upward (downward) motion 
season. Rodwell and Hoskins (1996) investigated the remote effect of the TP on the arid climate in North Africa using an idealized model. They showed clearly that the remote diabatic monsoon heating over the TP can induce a general region of descent associated with the linear Gill-type Rossby-wave pattern. This teleconnection pattern can also be seen clearly in Fig. 7b, d, in which the ascending motion forced by diabatic heating over the TP (outlined by the dashed black box) is associated with the descending motion over North Africa.

Removing the TP leads to more moisture convergence toward North Africa, accompanied by anomalous ascending motion over North Africa and anomalous descending motion over the TP (Fig. 8). This is the main reason for the precipitation increase in the rainy season over the North African region. In Stage-I (Fig. 8a, b), moisture transports coming from both the Indian Ocean and tropical Atlantic are enhanced in response to the TP removal, particularly in the southern part of North Africa. There is a clear moisture divergence over the TP (Fig. 8a), accompanied by strong anomalous descending motion (Fig. 8b), weakening moisture transport from the Indian Ocean to South Asia and, at the same time, promoting westward moisture transport into North Africa (Fig. 8a). On the Atlantic side, there is strong anomalous eastward moisture transport from the equatorial Atlantic $\left(0^{\circ}-20^{\circ} \mathrm{N}\right)$ (Fig. 8a), which contributes greatly to the moisture convergence over North Africa. This eastward moisture transport is driven by the anomalous warming in the northern tropical Atlantic (Fig. 6c). The northern tropical Atlantic warming in Stage-I attracts northward cross-equator moisture transport, which is deflected eastward toward North Africa. In Stage-II (Fig. 8c, d), although the moisture transport from the TP region becomes even stronger (Fig. 8e), the moisture transport from the tropical Atlantic stops (Fig. 8c, e). In this stage, the AMOC has been shut down, resulting in a strong cooling in the whole North Atlantic (Fig. 6f). The Atlantic ITCZ is thus shifted southward to the equator, leading to an anomalous southward cross-equatorial moisture transport to the South Atlantic (Fig. 8c, e). There is almost no moisture transport from the tropical Atlantic to North Africa (Fig. 8c), which finally reduces the precipitation over North Africa in Stage-II (Fig. 5a, 6). The ocean adjustment to the TP removal has a great impact on North African

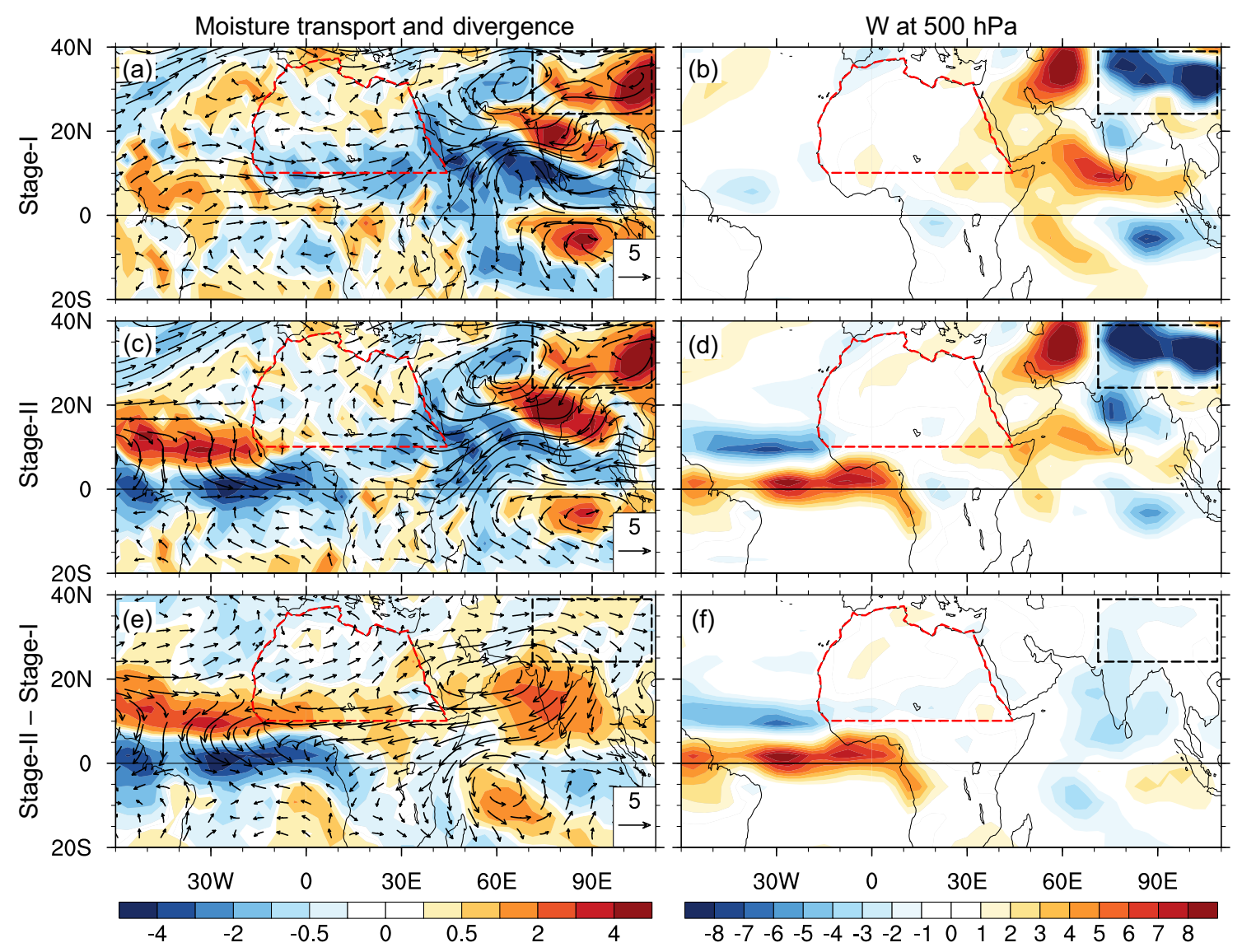

Fig. 8 Changes in (left column) vertically-integrated moisture transport (vector; $\boldsymbol{\rho} \bullet \vec{v} q$; units: $10^{-1} \mathrm{~kg} / \mathrm{m} / \mathrm{s}$ ) and its divergence (shading; $\rho \nabla \bullet(\vec{v} q)$; units: $10^{-5} \mathrm{~kg} / \mathrm{m}^{2} / \mathrm{s}$; positive for divergence and negative for convergence), and changes in (right column) vertical velocity at $500 \mathrm{hPa}\left(\mathrm{W} ; 10^{-1} \mathrm{~m} / \mathrm{s}\right)$ during the rainy season in NoTibet with respect to Real. $\rho$ is atmosphere density. $\mathbf{a}, \mathbf{b}$ are for Stage-I, and $\mathbf{c}, \mathbf{d}$, for Stage-II. e, $\mathbf{f}$ are differences (Stage-II minus Stage-I) 
precipitation. More details about the Atlantic response to the TP removal can be found in Yang and Wen (2020).

The surface cooling over North Africa after the TP removal (Fig. 6c, f) is also favorable for precipitation increase there. In the absence of the TP, the low clouds over most of the Eurasian continent are increased, particularly on the west side of the TP (Fig. 9a), which roughly determines the change in the absorbed shortwave (Fig. 9b). More low clouds and reduced incoming shortwave radiation imply more precipitable water in the atmosphere and less evaporation from the land surface, which helps ease the arid climate in North Africa. Here, the low clouds are defined as the total clouds below the level of $680 \mathrm{hPa}$, as in Zhang et al. (2010).

\section{Summary and discussion}

The existence of the TP has profound influence on the climate in Asia and North Africa. Through sensitivity experiments with and without the TP, we probe the impact of the TP on North African precipitation. Removing the TP leads to the cross-equatorial moisture transport deflected toward North Africa, which increases precipitation over North Africa significantly. Similar moisture transport change was found in a previous modeling study (Maffre et al. 2018), which suggested that removing the entire global orography leads to westward moisture transport across Africa from the Pacific to the Atlantic. However, the change in the Atlantic in response to the TP removal offsets partially the precipitation increase over North Africa by reducing the moisture transport from the tropical Atlantic to North Africa. We find in this present study that the TP impact on North African precipitation has two stages: one is the direct impact
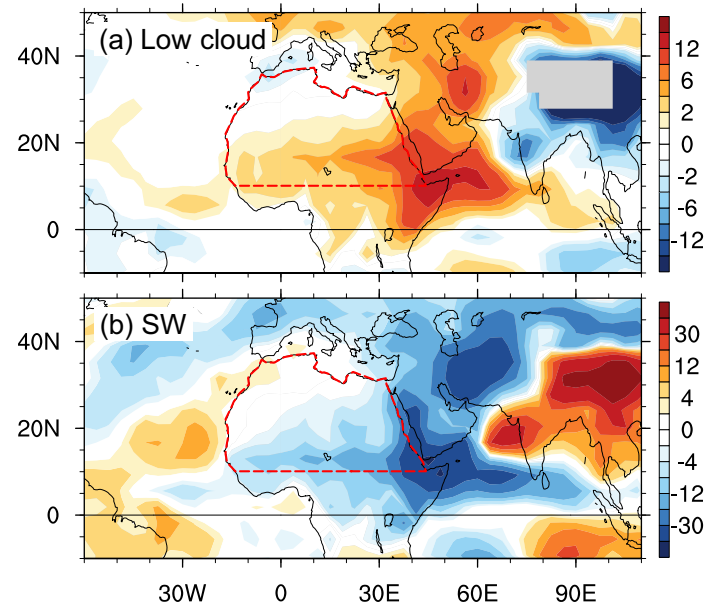

Fig. 9 a Percentage change of low cloud (units: \%), and $\mathbf{b}$ the change of net solar flux at surface (SW; units: $\mathrm{W} / \mathrm{m}^{2}$ ) during the rainy season in Stage-I of NoTibet with respect to Real. Low cloud is defined as clouds below $680 \mathrm{hPa}$ by regulating the pathway of the cross-equatorial moisture transport over the Indian Ocean and Arabian Sea, and the other is the indirect impact by regulating the strength of the AMOC. These two stages are summarized schematically in Fig. 10. Our results suggest that the uplift of the TP may have played an important role in the aridity of North Africa.

We focus on the changes during the rainy season in this paper. During the dry season, North African precipitation is hardly changed in response to the TP change (figures not shown). Removing the TP leads to a remarkable strengthening of the Indian winter monsoon, consistent with previous studies (e.g., Kitoh 2005). Consequently, more moisture can be transported from the Arabian Sea to North Africa. On the other hand, the ITCZ shifts toward the equator in the dry season, which, in turn, blocks the north-northwestward moisture transport from the Southern Hemisphere. These two moisture transport changes compensate each other, leading to a negligible change of North African precipitation during the dry season.

To better understand the coupled model results, we also carried out a pair of slab-ocean experiments using a higher-resolution atmosphere model. The slab-ocean model results are consistent with the coupled model results in Stage-I. Specifically, in response to the TP removal, precipitation increases throughout whole North Africa (Fig. 4d-f). There is a similar anomalous moisture
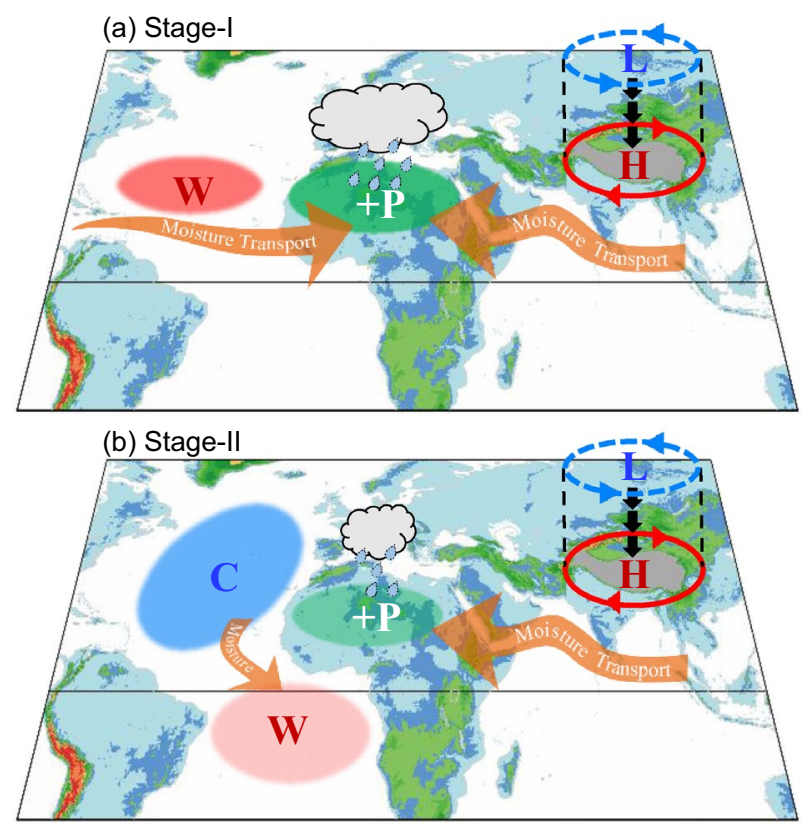

Fig. 10 Schematic diagram summarizing the main processes for North African precipitation change during the rainy season after the TP removal. a Atmosphere process (Stage-I), and $\mathbf{b}$ the feedback of ocean circulation to atmospheric circulation (Stage-II). The downward arrows represent descending motion. $H$ high pressure, $L$ low pressure, $+P$ precipitation increase, $C$ cooling, $W$ warming 
transport from the Indian Ocean and tropical Atlantic to North Africa as that in Stage-I of the coupled model results, leading to a substantial precipitation increase in North Africa.

This work quantifies the impact of the TP on North African precipitation in a coupled system, which helps our understanding of the TP's role in the global hydrological cycle. Previous studies mostly focused on the TP impact on Asian precipitation, while we highlight the teleconnection between the summer adiabatic heating over the TP and North African precipitation, providing a new mechanism for the formation of North African desert. The dynamic connection between these two regions was studied in Rodwell and Hoskins (1996) using an idealized atmospheric model. From the paleoclimatic perspective, our results suggest that the rapid uplift of the TP at 10-8 Ma may be responsible for the decrease of precipitation and consequent desertification in North Africa. Our results also support the argument that the aridity in the Asian interior and the establishment of the Indian and East Asian monsoons are linked to the uplift of the TP at 10-8 Ma (Copeland 1997; An et al. 2001). Moreover, our coupled model experiments suggest that a stronger AMOC may bring more precipitation to North Africa. Therefore, future change in the AMOC can cause precipitation anomaly over North Africa. In fact, as discussed in Sect. 1, previous studies showed that the weakening of the AMOC is of relevance to the aridity of North Africa (Mulitza et al. 2008; Stuut et al. 2008; Castañeda et al. 2009; Woollings et al. 2012).

There are many factors affecting North African precipitation in the real world. Paleoclimatic studies suggest that the Tethys Sea shrinkage during the Late Miocene may have caused the aridity in North Africa (Zhang et al. 2014). The African monsoon is also sensitive to small change in the incoming solar radiation (Noblet et al. 1996). Other forcing mechanisms (such as atmospheric $\mathrm{CO}_{2}$ concentration, vegetation types, distribution of sea surface temperature, river routing, extent of ice sheets) may also have considerable influences on North African climate (Liu and Yin 2002). We are also aware that our results presented here may be model dependent. Therefore, to better understand the linkage between the TP uplift and North African aridity, more geological information should be collected, and different coupled models and more welldesigned experiments are needed in future.

Acknowledgements This work is supported by the NSF of China (nos. 91737204 and 41725021). All experiments were performed on the supercomputers at the LaCOAS, Peking University, and at the Chinese National Supercomputer Centre in Tianjin (Tian-He No.1).

Open Access This article is licensed under a Creative Commons Attribution 4.0 International License, which permits use, sharing, adaptation, distribution and reproduction in any medium or format, as long as you give appropriate credit to the original author(s) and the source, provide a link to the Creative Commons licence, and indicate if changes were made. The images or other third party material in this article are included in the article's Creative Commons licence, unless indicated otherwise in a credit line to the material. If material is not included in the article's Creative Commons licence and your intended use is not permitted by statutory regulation or exceeds the permitted use, you will need to obtain permission directly from the copyright holder. To view a copy of this licence, visit http://creativecommons.org/licenses/by/4.0/.

\section{References}

An Z, Kutzbach JE, Prell WL, Porter SC (2001) Evolution of Asian monsoons an phased uplift of the Himalaya-Tibetan Plateau since Late Miocene times. Nature 411:62-66

Castañeda IS, Mulitza S, Schefuß E, Santos RALD, Damsté JSS, Schouten S (2009) Wet phases in the Sahara/Sahel region and human migration patterns in North Africa. Proc Natl Acad Sci USA 106:20159-20163

Chen B, Xu X-D, Yang S, Bian J-C (2012) On the characteristics of water vapor transport from atmosphere boundary layer to stratosphere over Tibetan Plateau regions in summer. Chin J Geophys 55:406-414

Chris F, Owen J, Ward NM et al (1991) Prediction of seasonal rainfall in the sahel region using empirical and dynamical methods. J Forecast 10:21-56

Copeland P (1997) The when and where of the growth of the Himalaya and the Tibetan Plateau. In: Ruddiman WF (ed) Tectonic uplift and climate change. Plenum, New York, pp 20-36

Curio J, Maussion F, Scherer D (2015) A 12-year high-resolution climatology of atmospheric water transport over the Tibetan Plateau. Earth Syst Dyn 6:109-124

deMenocal PB (1995) Plio-Pleistocene African climate. Science 270:53-53

Duan AM, Wu GX (2005) Role of the Tibetan Plateau thermal forcing in the summer climate patterns over subtropical Asia. Clim Dyn 24:793-807

Faure H, Denard LF (1998) Sahara environmental changes during the quaternary and their possible effect on carbon storage. In: Issar AS, Brown N (eds) Water, environment and society in times of climatic change. Springer, Dordrecht, pp 319-322

Flohn H, Reiter ER (1968) Contributions to a meteorology of the Tibetan Highlands. In: Atmos. Sci. Paper No. 130, Colorado State University, Ft.Collins, p 120

Harada C (2003) Seasonal and year-to-year variations of rainfall in the Sahara desert region based on TRMM PR data. Geophys Res Lett 30:1288-1291

Harrison TM, Copeland P, Kidd WS, Yin A (1992) Raising Tibet. Science 255:1663-1670

Hulme M (1992) Rainfall changes in Africa: 1931-1960 to 1961-1990. Int J Climatol 12:685-699

Hunke EC, Lipscomb WH (2010) CICE: the Los Alamos Sea Ice Model, documentation and software user's manual, version 4.1. Version 4.0, LA-CC-06-012, Los Alamos National Laboratory

Ji G, Yao L, Yuan F, Yang H (1986) Characteristics of surface and atmospheric heating fields over Qinghai-Xizang Plateau during the winter in 1982. Sci Sin 29:876-888

Kitoh A (2005) Climate model simulation on the role of mountain uplift on Asian monsoon. J Geol Soc Jpn 111:654-667 ((in Japanese))

Knippertz P, Fink AH (2008) Dry-season precipitation in Tropical West Africa and its relation to forcing from the extratropics. Mon Weather Rev 136:3579-3596 
Kutzbach JE, Liu Z (1997) Response of the African monsoon to orbital forcing and ocean feedbacks in the middle Holocene. Science 278:440-443

Kutzbach JE, Guetter PJ, Ruddiman WF, Prell WL (1989) Sensitivity of climate to late Cenozoic uplift in southern Asia and the American west: numerical experiments. J Geophys Res Atmos 94:18393-18407

Kutzbach JE, Prell WL, Ruddiman WF (1993) Sensitivity of Eurasian climate to surface uplift of the Tibetan Plateau. J Geol 101:177-190

Lamb PJ (1983) West African water vapor variations between recent contrasting Subsaharan rainy seasons. Tellus A 35:198-212

Lawrence DM et al (2012) The CCSM4 land simulation, 1850-2005: assessment of surface climate and new capabilities. J Clim 25:2240-2260

Liu X, Yin Z-Y (2002) Sensitivity of East Asian monsoon climate to the Tibetan Plateau uplift. Sci Atmos Sin 183:223-245

Lu CX, Yu G, Xie GD (2005) Ieee: Tibetan plateau serves as a water tower. In: IEEE international geoscience \& remote sensing symposium, 2005, pp 3120-3123

Maffre P, Ladant JB, Donnadieu Y, Sepulchre P, Godderis Y (2018) The influence of orography on modern ocean circulation. Clim Dyn 50:1277-1289

Molnar P, England P, Martinod J (1993) Mantle dynamics, uplift of the Tibetan Plateau, and the Indian Monsoon. Rev Geophys 31:357-396

Mulitza S et al (2008) Sahel megadroughts triggered by glacial slowdowns of Atlantic meridional overturning. Paleoceanography 23

Noblet ND, Braconnot P, Joussaume S, Masson V (1996) Sensitivity of simulated Asian and African summer monsoons to orbitally induced variations in insolation 126, 115 and 6 kBP. Clim Dyn 12:589-603

Park S, Bretherton CS, Rasch PJ (2014) Integrating cloud processes in the community atmosphere model, version 5. J Clim 27:6821-6856

Pausata FSR, Gaetani M, Messori G, Berg A, Demenocal PB (2020) The greening of the Sahara: past changes and future implications. One Earth 2:235-250

Rodwell MJ, Hoskins BJ (1996) Monsoons and the dynamics of deserts. Q J R Meteorol Soc 122:1385-1404

Ruddiman WF, Raymo ME, Prell WL, Kutzbach JE (1997) The upliftclimate connection: a synthesis. In: Ruddiman WF (ed) Tectonic uplift and climate change. Plenum, New York, pp 471-515

Schuster M, Duringer P, Ghienne J-F, Vignaud P, Mackaye HT, Likius A, Brunet M (2006) The age of the Sahara Desert. Science 311:821-821

Smith RS, Gregory JM (2009) A study of the sensitivity of ocean overturning circulation and climate to freshwater input in different regions of the North Atlantic. Geophys Res Lett 36:L15701

Stuut JBW et al (2008) Coherent high- and low-latitude control of the northwest African hydrological balance. Nat Geosci 1:670-675

Su B, Jiang D, Zhang R, Sepulchre P, Ramstein G (2018) Difference between the North Atlantic and Pacific meridional overturning circulation in response to the uplift of the Tibetan Plateau. Clim past 14:751-762

Tucker CJ, Dregne HE, Newcomb WW (1991) Expansion and contraction of the Sahara Desert from 1980 to 1990. Science 253:299-300

Wai MK, Smith EA, Bessemoulin P, Culf AD, Dolman AJ, Lebel T (1997) Variability in boundary layer structure during HAPEXSahel wet-dry season transition. J Hydrol 188-189:956-997

Wen Q, Yang H (2020) Investigating the role of the Tibetan Plateau in the formation of Pacific meridional overturning circulation. J Clim 33:3603-3617

Woollings T, Gregory JM, Pinto JG, Reyers M, Brayshaw DJ (2012) Response of the North Atlantic storm track to climate change shaped by ocean-atmosphere coupling. Nat Geosci 5:313-317

Wu G, Liu Y, Dong B, Liang X, Duan A, Bao Q, Yu J (2012) Revisiting Asian monsoon formation and change associated with Tibetan Plateau forcing: I. Formation. Clim Dyn 39:1169-1181

Xie P, Arkin PA (1997) Global precipitation: a 17-year monthly analysis based on gauge observations, satellite estimates, and numerical model outputs. Bull Am Meteorol Soc 78:2539-2558

Xu X, Lu C, Shi X, Gao S (2008) World water tower: an atmospheric perspective. Geophys Res Lett 35:525-530

$\mathrm{Xu} X$ et al (2014) An important mechanism sustaining the atmospheric "water tower" over the Tibetan Plateau. Atmos Chem Phys 14:11287-11295

Yanai M, Li C, Shan S (1992) Seasonal heating of the Tibetan plateau and its effects on the evolution of the Asian Summer Monsoon. J Meteorol Soc Jpn 70:319-351 ((in Japanese))

Yang H, Wen Q (2020) Investigating the role of the Tibetan plateau in the formation of Atlantic meridional overturning circulation. J Clim 33:3585-3601

Yang H, Li Q, Wang K, Sun Y, Sun D (2015) Decomposing the meridional heat transport in the climate system. Clim Dyn 44:2751-2768

Yang H, Shen X, Yao J, Wen Q (2020) Portraying the Impact of the Tibetan Plateau on global climate. J Clim 33:3565-3583

Yeh TC, Gao Y (1979) Meteorology of the Qinghai-Xizang Plateau. Science Press, Beijing, pp 1-278 ((in Chinese))

Zhang R, Kang SM, Held IM (2010) Sensitivity of climate change induced by the weakening of the Atlantic meridional overturning circulation to cloud feedback. J Clim 23:378-389

Zhang Z, Ramstein G, Schuster M, Li C, Contoux C, Yan Q (2014) Aridification of the Sahara desert caused by Tethys Sea shrinkage during the Late Miocene. Nature 513:401-404

Zhou XJ, Zhao P, Chen JM, Chen LX, Weiliang LI (2009) Impacts of thermodynamic processes over the Tibetan Plateau on the Northern Hemispheric climate. Sci China 052:1679-1693

Publisher's Note Springer Nature remains neutral with regard to jurisdictional claims in published maps and institutional affiliations. 